\title{
Research and application of flipped classroom based on BB platform in computer basic course
}

\author{
Yan Tang, Aiqing Han,Renquan Liu, Shuzhen Li \\ Information Center Beijing University of Chinese Medicine Beijing 100029, China \\ E-Mail: tangyan97_1017@sina.com \\ Correspondence to: Shuzhen Li, Information Center \\ E-Mail: shuzhenli2011@163.com
}

Keywords: BB platform; flipped classroom; case teaching; E-learning; MOOC

\begin{abstract}
This paper introduces the application of flipped classroom and case teaching in the basic course of computer based on BB platform. This course provides students with a free, developed learning environment, online learning platform on the BB. And the course combines the flipping classroom teaching philosophy and case teaching method, the reform of teaching content in a computer-based curriculum of medical colleges and universities, teaching methods, teaching process, teaching mode, students analyze and solve problems capacity, as well as self-learning and lifelong learning skills. This study is a very important reference for the study and reform the teaching mode and structure of other courses.
\end{abstract}

\section{Introduction}

Computer basic course is a university freshman in public courses, through this course training information literacy of the students, to enable students to adapt to the future work of computer technology, network technology, multimedia technology and information technology needs. Therefore, it is necessary to deepen the teaching reform of computer basic course in Colleges and universities. However, at present, many colleges and universities are faced with difficulty of the computer basic courses reduce the time of teaching. How do we reduce the hours in the case, do not reduce the content of teaching? Flipped classroom is the best solution.

This paper introduces the application of flipped classroom and case teaching in the basic course of computer based on BB platform. This course provides students with a free, developed learning environment, online learning platform on the BB. And the course combines the flipping classroom teaching philosophy and case teaching method, the reform of teaching content in a computer-based curriculum of medical colleges and universities, teaching methods, teaching process, teaching mode. After two rounds teaching practices, the teaching effectiveness is good, the student and teacher's educational reform to this curriculum are satisfied. The educational reform experience of this course has good implication to other curricula, and it is worth promote. 


\section{2. background and educational reform plan}

\subsection{Traditional teaching has many shortcomings}

(1) the course content needs to renew place

With the rapid development of computer technology, the breadth and depth of students' computer knowledge have higher requirements. However, the computer basic course affected areas of many university are narrow, cannot meet the need of student.

(2) has the teacher for the leadership "full house fills" phenomenon

Computer basic course main teaching way is primarily the teacher to explain, is still traditional "teacher said that the student listened". In the classroom, the teacher has the dominant position, the student passive receive knowledge, has not transferred the enthusiasm and initiative of student fully, has "full house to fill" phenomenon.

\section{(3)BB platform utilization ratio is not high}

After many years of construction, the BB platform teaching material of computer base is quite complete, but teachers' and students' use to the BB platform, is mainly primarily downloading the curriculum related teaching material, the BB platform powerful function has not obtained the full excavation and use.

\subsection{The solution of issue}

According to the problem that in computer basic course has, the reform of computer basic course takes the $\mathrm{BB}$ web platform as the carrier, provides a free and open learning environment for the student, reforms the course content, according to the course content, and "turn over classroom" teaching idea unifies the case-teaching method and driven with projects teaching method, to Chinese medicine colleges the teaching method, the teaching flow of, the educational model computer basic course reformed, raises the computer operation level of student, trains the student appliance computer technology solution specific issue the ability, as well as trains the student in the Internet age, uses MOOC to carry on the study the custom.

\section{3. all-around educational reform}

\section{1 reform course content}

According to research and computer expert advice, we adjust the content of computer basic courses.In teaching the course content, the teachers are required to teach the knowledge of the case point to a way to show to students, computer knowledge and practical application, in close connection with the medical profession to solve practical problems. Some chapters, requires teachers based on students' professional differences, the use of multiple versions of teaching cases, greatly stimulate students' interest in learning, and the ability to train students to use computer processing problem in their own profession.

\section{2 reform teaching flow}

This course uses case and flipped classroom teaching as the main teaching methods in the BB platform, therefore, the teaching process and traditional classroom teaching process is completely different.

\section{(1) before class}

Flipped classroom teaching process, teachers are required before class advance ready for students to learn video, PPT and other information and knowledge tests and provide a list of 
learning to enable the students to learn before class. Teachers management all study task in the BB platform, before class, students must complete the study task.

\section{(2) class}

In class, the teacher summarizes key points of knowledge, and help students quickly master key and difficult knowledge points. Then, the teacher according to students' learning problems encountered, discuss, and conduct case-based teaching activities, teachers throughout counseling. After completing the case, the students show their work, the teacher summarizes the completion of the case, and gives recommendations for improvement.

\section{(3) after class}

Teachers summarize all aspects of teaching, and teachers based on student feedback to improve it. Meanwhile, in the BB platform, teachers to answer students' questions, students modification works according to teacher recommendations, and complete learning tasks before the next class.

The teaching flow of flipped classroom as shown in Fig. 1:

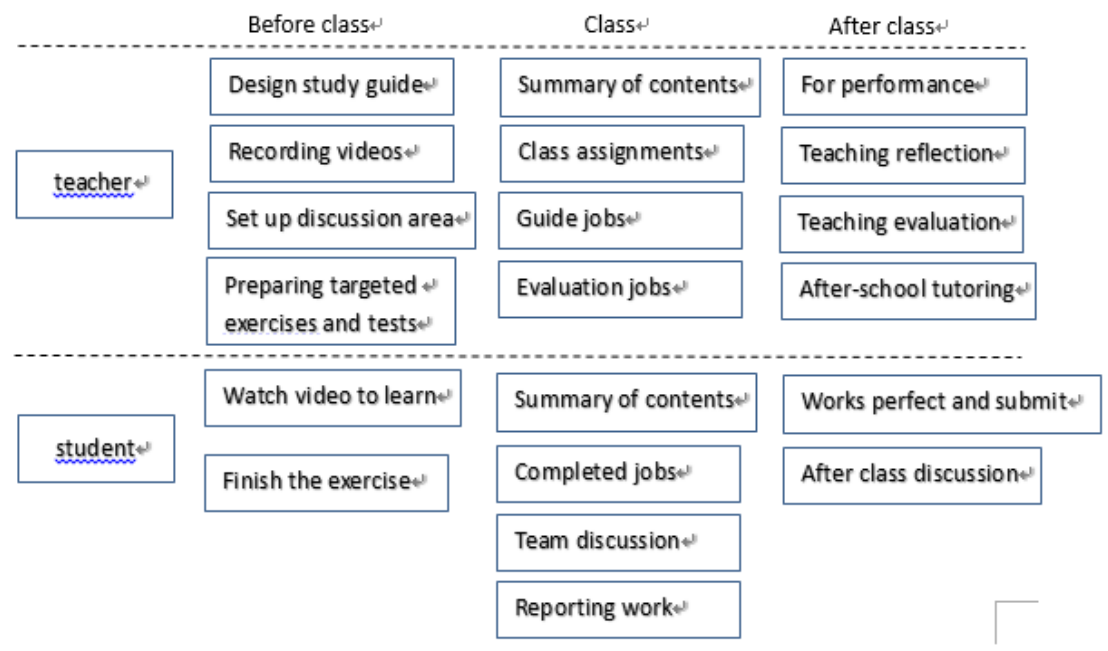

Fig 1 the teaching flow of flipped classroom

\section{3 carries on the Flipped classroom in the BB platform}

BB network teaching platform has been used for many years in my school, using BB platform to carry out flipped classroom teaching can save costs. Course group of teachers through continuous research and experimentation in the BB platform can be carried out completely flipped classroom teaching. Before class, the curriculum group of teachers completed the following work in the BB platform:

\section{(1) Design study guide}

Guide mainly introduces students to learn in this chapter of the document main content, key points, such as the introductory document. It can take videos, Word documents, PPT or other forms of display to the students.

\section{(2) Recording videos}

Before flipped classroom lessons to learn from the video data, mainly on knowledge, video can not be too long, generally 5 minutes is appropriate. Through the video study, grasps the knowledge node of related chapter, builds the foundation for the smooth carry out flipped classroom. 


\section{(3) Preparing targeted exercises and tests}

Teachers prepare online exercises and tests on the BB platform. Students through targeted exercises, and online testing, which can help students acquire knowledge and to inspire students to think deeply.

\section{(4) Set up course discussion areas}

In the process of learning when students encounter questions can be posted to the discussion area, the teacher or other students can answer and discuss.

\subsection{Reform the way of examination}

The computer basic course after reform cancels the terminal examinations, pays great attention to the learning process of student. Disperses the result in all practices and tests of course teaching, through practices and tests progressively accumulates the result, finally calculates the result in the result center of BB platform.

\section{4. conclusions}

Research and application of flipped classroom based on BB platform in computer basic course is a new topic. In the process of curriculum reform, teacher of the course group make a lot of useful attempts and in-depth study. After two rounds of the experiment, the effect is very good, BB platform combined with flipping the classroom teaching mode is very suitable for computer-based instruction. However, in the flipped classroom teaching, if students do not have to learn before class will affect the teaching effect. Group members are also actively discussed how to better supervise students in the BB platform before class. This study is a very important reference for the study and reform the teaching mode and structure of other courses.

\section{Acknowledgment}

This work was supported by the 2015-Beijing University of Chinese medicine education science research project of Reform and practice of the teaching of basic computer research under Grant No. XJY15004.

\section{Reference}

[1] A. McAuley, B. Stewart, G.Siemens and D.Cormier. The MOOC Model for Digital Practice [EB/OL]. University of Prince Edward Island, Social Sciences and Humantities Research Council's Knowledge Synthesis Grants on the Digital Economy(2010).http://davecormier.com/edblog/wpcontent/uploads/MOOC_Final.pdf.

[2] J.Bergamnn \& A. Sams. How the Flipped Classroom Is Radically Transforming Leaning [EB/OL].http://www.thedailyriff.com/articles/How-the-flipped-classroom-is-radically-transforming -leaning-536.php,2014-12-12. Journal of NanJingxiaozhuang university.2015, 11(6).

[3] WANG Shiwei. The application of basic medicine computer and information technology[M]. Tsinghua University press, 2011,9

[4] ZhangYueguo, Zhang Yujiang. Perspective "flipping classroom" [J]. information technology education in primary and middle schools, 2012(3): 9-10

[5] XIE Yanhong. Research of task-driven flipped classroom teaching model[J]. Journal of Dezhou university, 2014,30(4):7-12 
[6] Ma Xiulin, Zhao Guoqing \& Wu Tong. An Empirical Study on the Influence of Flipped Classroom Model on Information Technology Course Teaching[J]. Journal of distance education, 2013(1): 79-85 